\title{
MATRIK
}

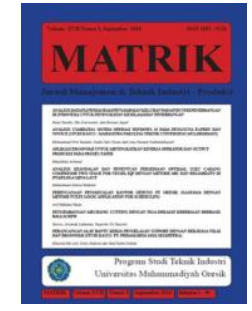

\section{Perancangan Alat Penyaring Bubur Kedelai dan Alat Press Bubur Kedelai Yang Ergonomis Pada Industri Tahu}

\author{
Muhammad Rafi Wardana $^{1^{*}}$, Lina Dianati Fathimahhayati ${ }^{2 *}$, Theresia Amelia Pawitra ${ }^{3 *}$ \\ Program Studi Teknik Industri, Universitas Mulawarman Jl. Sambaliung No.9, Kampus Gunung \\ Kelua, Samarinda 75119, Kalimantan Timur, Indonesia \\ fteknik.unmul@ft.unmul.ac.id
}

\begin{tabular}{|c|}
\hline INFO ARTIKEL \\
\hline 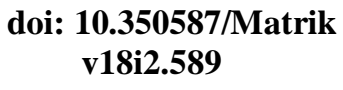 \\
\hline $\begin{array}{l}\text { Jejak Artikel : } \\
\text { Upload artikel } \\
\text { O4 Maret } 2020 \\
\text { Revisi oleh reviewer } \\
\text { O6 Agustus } 2020 \\
\text { Publish } \\
16 \text { September } 2020\end{array}$ \\
\hline
\end{tabular}

Kata Kunci :

CATIA, Ergonomis, MSDs
ABSTRAK

Pabrik Tahu Pak Kasimin merupakan salah satu industri tahu yang memproduksi tahu mentah dan tahu goreng. Pabrik yang berlokasi di Kelurahan Selili Kota Samarinda ini telah beroperasi sejak tahun 30 lalu dengan target produksi perharinya yaitu $150 \mathrm{~kg}$ tahu. Target produksi yang cukup besar ini menimbulkan berbagai keluhan oleh pekerjanya, salah satunya yaitu keluhan musculoskeletal disorders pada stasiun kerja penyaringan bubur kedelai. Hasil observasi dan wawancara oleh 2 pekerja pada stasiun kerja penyaringan bubur kedelai menunjukkan bahwa pekerja mengeluhkan sakit pada lengan atas kiri, lengan atas kanan, punggung dan pinggang, sedangkan hasil identifikasi musculoskeletal disorders menggunakan Nordic Body Map didapatkan skor sebesar 59 pada pekerja bernama Sandi dan skor sebesar 56 pada pekerja bernama Alfin. Berdasarkan hal tersebut, pekerja pada stasiun kerja penyaringan bubur kedelai membutuhkan alat yang ergonomis agar dapat menanggulangi risiko postur kerja yang tidak ergonomis. Penelitian ini bertujuan untuk melakukan perancangan alat penyaring bubur kedelai dan alat press bubur kedelai yang didesain menggunakan software CATIA V5 dan dirancang sesuai dengan ukuran antropometri pekerja dengan menggunakan mekanisme kerja yaitu memutar tuas sebagai solusi dalam menanggulangi postur kerja tidak ergonomis. 


\section{Pendahuluan}

Berdasarkan hasil Riset Kesehatan Dasar (Riskesdas) pada tahun 2013, menyatakan bahwa prevalensi penyakit sendi bedasarkan hasil diagnosis tenaga kesehatan di Indonesia sebesar 11,9\% dan berdasarkan diagnosis atau gejala sebesar $24,7 \%$. Selain itu berdasarkan hasil survei terhadap prevalensi nyeri punggung bawah karena posisi duduk sebesar $39,7 \%$ dimana, $12,6 \%$ sering menimbulkan keluhan, $1,2 \%$ kadang-kadang menimbulkan keluhan dan $26,9 \%$ jarang menimbulkan keluhan [1].

Keluhan musculoskeletal disorders dialami oleh pekerja pabrik Tahu dikota Samarinda, yaitu pekerja dari Pabrik Tahu Pak Kasimin. Pabrik tahu ini berlokasi dijalan Lumba-lumba Kelurahan Selili, Samarinda. Pabrik ini beroperasi setiap harinya selama 12 jam dengan target produksi sebesar $150 \mathrm{~kg}$ tahu per hari. Empat orang pekerja Pabrik Tahu Pak Kasimin merasakan keluhan musculoskeletal berupa cedera otot dan pegal pada persendiaan. Keluhan musculoskeletal tersebut seringkali dirasakan pekerja pada stasiun kerja penyaringan bubur kedelai. Cedera ini pada umumnya disebut sebagai cedera okupasional atau cedera pekerjaan.

Berdasarkan penelitian yang telah dilakukan sebelumnya, terdapat $20 \%$ penyakit akibat kerja berupa cedera dan terdapat $11 \%$ penyakit akibat kerja berupa pegal pada persendian dalam proses pembuatan tahu [2]. Timbulnya cedera ini diakibatkan aktivitas manual material handling atau pemindahan barang dengan menggunakan tenaga manusia, cedera pada otot ini merupakan salah satu risiko dari postur pekerja yang salah atau beban material yang diangkat terlalu berat. Postur kerja yang salah dan dilakukan secara terusmenerus serta dalam durasi yang panjang diikuti dengan beban material yang melebihi batas kekuatan angkut pekerja akan berakibat fatal apabila tidak diberikan perhatian yang serius.

Istilah ergonomi dikenal dalam bahasa Yunani, dari kata ergos dan nomos yang memiliki arti "kerja" dan "aturan atau kaidah", dari dua kata tersebut secara pengertian bebas sesuai dengan perkembangannya, yakni suatu aturan atau kaidah yang ditaati dalam lingkungan pekerjaan [3]. Sejarah perkembangan ergonomi paralel dengan sejarah peradaban manusia itu sendiri, usaha terus menerus dengan mempertimbangkan kemampuan dan keterbatasan manusia untuk mengembangkan peralatan dan sistem untuk mengatasi kekurangan dan meningkatkan kemampuan [4].

Tujuan utama dari ergonomi adalah mempelajari batasan-batasan pada tubuh manusia dalam berinteraksi dengan lingkungan kerjanya baik secara jasmani maupun psikologis. Selain itu juga untuk mengurangi datangnya kelelahan yang terlalu cepat dan menghasilkan suatu produk yang nyaman, enak dipakai oleh pemakainya [5].

Musculoskeletal Disorders (MSDs) merupakan suatu gangguan musculoskeletal yang ditandai dengan terjadinya sebuah luka pada otot, tendon, ligament, saraf, sendi, kartilago, tulang atau pembuluh darah pada tangan, kaki, kepala, leher, atau punggung [6]. Apabila otot menerima beban statis secara berulang dalam jangka waktu yang lama dapat menyebabkan kerusakan pada sendi, ligamen dan tendon. Keluhan muskuloskeletal lazim dialami pekerja yang melakukan gerakan monoton dan berulang terus menerus [7].

Nordic Body Map merupakan kuesioner yang paling sering digunakan untuk mengetahui ketidaknyamanan pada para pekerja, yang terstandarisasi dan tersusun rapi. Tujuan dari kuesioner dari Nordic Body Map yakni untuk mengetahui bagian tubuh dari pekerja yang terasa sakit sebelum dan sesudah melakukan pekerjaan [8].

RULA (Rapid Upper Limb Assessment) merupakan metode yang dikembangkan dalam bidang ergonomi yang menginvestasikan dan menilai posisi kerja yang dilakukan oleh tubuh bagian atas. Peralatan ini tidak melakukan peranti khusus dalam memberikan pengukuran postur leher, punggung dan tubuh bagian atas sejalan dengan fungsi otot dan beban eksternal yang ditopang oleh tubuh [9].

Istilah anthropometri berasal dari kata "anthro" yang berarti manusia dan "metri" yang berarti ukuran. Secara definitif anthropometri dapat dinyatakan sebagai satu studi yang berkaitan dengan pengukuran dimensi tubuh manusia [10].

Antropometri dapat dibagi atas antropometri struktural (statis) dan antropometri fungsional (dinamis). Antropometri statis adalah pengukuran keadaan dan ciri-ciri fisik manusia dalam posisi diam pada dimensi-dimensi dasar fisik, meliputi panjang segmen atau bagian tubuh, lingkar bagian tubuh, massa bagian tubuh dan sebagainya. Antropometri dinamis adalah pengukuran keadaan dan ciri-ciri fisik 
manusia ketika melakukan gerakan-gerakan yang mungkin terjadi saat bekerja, berkaitan erat dengan dimensi fungsional, misalnya tinggi duduk, panjang jangkauan, dan lain-lain [11].

Dalam konsep persentil ini ada dua konsep yang perlu dipahami. Pertama, persentil antropometri pada individu hanya didasarkan pada satu ukuran tubuh saja, seperti tinggi berdiri atau tinggi duduk. Kedua, tidak ada orang yang disebut sebagai orang persentil ke90 atau orang persentil ke-5 [12].

Proses perancangan produk menurut Nigel Cross terbagi atas tujuh langkah yang masingmasing mempunyai metode tersendiri. Ketujuh langkah tersebut yaitu klarifikasi tujuan, penetapan fungsi, penetapan kebutuhan, penentuan karakteristik, pembangkitan alternatif, evaluasi alternatif, dan rincian perbaikan. Definisi masalah dan pemecahan strategi yang terdapat dalam metodologi ini menyediakan cara baru yang kuat untuk mengelola risiko yang terkait dengan drive untuk terus meningkatkan yang sudah ada atau membuat kemampuan manufaktur yang baru [13].

Hasil observasi dan wawancara yang telah dilakukan sebelumnya diketahui bahwa pekerja pada stasiun kerja penyaringan bubur kedelai membutuhkan alat penyaring bubur kedelai yang ergonomis agar dapat menanggulangi keluhan musculoskeletal disorders yang dialami oleh pekerja. Berdasarkan hal tersebut, penelitian ini bertujuan untuk melakukan perancangan alat penyaring bubur kedelai dan alat press bubur kedelai yang sesuai dengan antropometri pekerja dengan menggunakan mekanisme kerja memutar tuas sebagai solusi untuk mengurangi risiko postur kerja tidak ergonomis. Perancangan alat penyaring bubur kedelai dan alat press bubur kedelai di desain dengan menggunakan software CATIA V5.

\section{Metode Penelitian}

Penelitian ini dilakukan pada Pabrik Tahu Pak Kasimin yang berlokasi di Jl. Lumba-lumba Kelurahan Selili, Samarinda. Waktu penelitian dari bulan November 2019 sampai bulan Januari 2020. Tahap penelitian terdiri dari 4 tahapan.

\subsection{Tahap Identifikasi Masalah}

Pada tahap ini identifikasi masalah, peneliti melakukan observasi langsung dan melakukan wawancara serta studi literatur, sehingga masalah yang ada dapat teridentifikasi. Responden pada penelitian ini terfokus kepada 2 pekerja yang bekerja pada stasiun kerja penyaringan bubur kedelai. Pengumpulan data pada penelitian ini dilakukan selama 3 bulan. Asumsi dan batasan masalah pada penelitian ini yaitu tidak dilakukan perhitungan biaya pada proses perancangan, penelitian ini hanya berfokus pada stasiun kerja penyaringan bubur kedelai dan perancangan alat ini hanya diperuntukkan bagi pekerja yang bekerja saat penelitian ini dilakukan. Tujuan dari penelitian ini adalah melakukan perancangan yang sesuai dengan antropometri pekerja agar dapat menanggulangi postur kerja tidak ergonomis dan meminimalisisr keluhan musculoskeletal disorders.

\subsection{Tahap Pengumpulan Data}

Pada tahap pengumpulan data, terdapat 2 jenis data yang dikumpulkan yaitu data primer yang berupa data profil usaha pabrik tahu, proses pembuatan tahu, data antropometri pekerja pabrik tahu seperti lebar bahu pekerja, diameter lingkar genggam tangan pekerja, tinggi bahu berdiri pekerja, lebar tangan pekerja, dan tinggi siku berdiri pekerja. Selain itu terdapat juga keluhan penyakit akibat kerja yang didapat melalui hasil wawancara pekerja dengan menggunakan bantuan kuisioner Nordic Body Map, postur kerja tidak ergonomis pada stasiun kerja penyaringan bubur kedelai dan data ukuran dimensi fasilitas kerja seperti alat pengayun bubur kedelai, meja pengepress tahu, dan alat pencetak tahu . Data sekunder terdiri dari jurnal atau literatur dan buku tentang ergonomi.

\subsection{Tahap Pengolahan Data}

Pada tahap pengolahan data dilakukan tahap identifikasi terhadap keluhan MSDs menggunakan Nordic Body Map dan identifikasi terhadap postur kerja tidak ergonomis, selanjutnya tahap evaluasi yang dilakukan dengan menggunakan RULA Analysis pada software CATIA V5 terhadap postur kerja dari pekerja yang bekerja di stasiun kerja penyaringan bubur kedelai sehingga 
nantinya diketahui skor tingkat risiko dari postur kerja tiap pekerja pabrik. Selanjutnya dilakukan perancangan alat pada Pabrik Tahu Pak Kasimin yang dapat diterapkan secara berkelanjutan dengan menggunakan metode perancangan produk.

\subsection{Tahap Analisis Hasil}

Pada tahap analisis hasil ini dilakukan analisis terhadap keluhan MSDs yang dirasakan pekerja, menganalisis postur kerja pada stasiun penyaringan bubur kedelai menganalisis hasil rekomendasi perbaikan yang diusulkan oleh peneliti.

\section{Hasil dan Pembahasan}

Pada proses penyaringan bubur kedelai di Pabrik Tahu Pak Kasimin, terdapat 2 pekerja yang bekerja pada stasiun kerja tersebut, yaitu pekerja bernama Sandi dan Alfin. Pada pekerja bernama Sandi didapatkan skor 1 (tidak sakit) pada bagian tubuh leher atas, leher bawah, pantat, paha kiri, paha kanan, lutut kiri, lutut kanan, betis kiri, betis kanan, pergelangan kaki kiri dan kanan, kaki kiri dan kaki. Skor 3 (sakit) pada bagian tubuh bahu kiri, bahu kanan, punggung, siku kiri, siku kanan, lengan bawah kiri, lengan bawah kanan, pergelangan tangan kiri, pergelangan tagan kanan, tangan kiri dan kanan. Skor 4 (sangat sakit) pada bagian tubuh lengan atas kiri, lengan atas kanan dan pinggang.

Pada pekerja bernama Alfin didapatkan skor 1 (tidak sakit) pada bagian tubuh leher atas, leher bawah, pantat, paha kiri, paha kanan, lutut kiri, lutut kanan, betis kiri, betis kanan, pergelangan kaki kiri dan kanan, kaki kiri dan kaki. Skor 2 (agak sakit) pada bagian tubuh siku kiri, siku kanan, tangan kiri, dan tangan kanan. Skor 3 (sakit) pada bagian tubuh bahu kiri, bahu kanan, lengan bawah kiri, lengan bawah kanan, pergelangan tangan kiri dan pergelangan tagan kanan. Skor 4 (sangat sakit) pada bagian tubuh lengan atas kiri, lengan atas kanan, puggung dan pinggang. Rekapitulasi hasil skor total individu pada keluhan MSDs berdasarkan kuisioner Nordic Body Map ditunjukkan pada Tabel 1.

Tabel 1. Hasil Total Skor Individu Sandi

\begin{tabular}{|c|c|}
\hline Pekerja & Skor \\
\hline Sandi & 59 \\
\hline Alfin & 56 \\
\hline
\end{tabular}

Berdasarkan hasil perhitungan yang telah dilakukan, dapat diketahui hasil total skor individu dari Sandi yaitu sebesar 59 dan Alfin yaitu sebesar 56, sehingga dapat diketahui bahwa perlu dilakukan tindakan perbaikan di kemudian hari.

Setelah dilakukan identifikasi menggunakan Nordic Body Map, maka tahap selanjutnya adalah melakukan evaluasi terhadap postur kerja dari proses penyaringan bubur kedelai. Postur kerja yang dilakukan oleh pekerja bernama Alfin dapat dilihat pada Gambar 1.

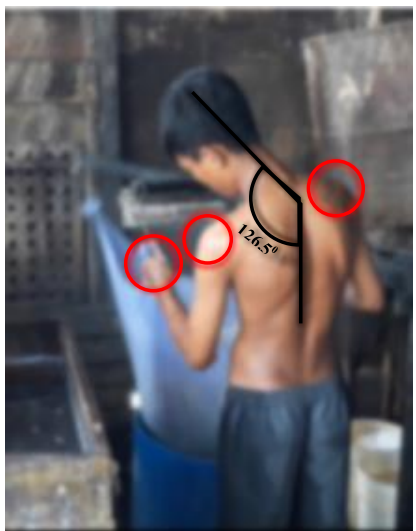

Gambar 1. Proses Penyaringan Bubur Kedelai

Evaluasi proses penyaringan bubur kedelai ini dilakukan terhadap pekerja bernama Alfin menggunakan RULA Analysis pada software CATIA V5 dapat dilihat pada Gambar 2.

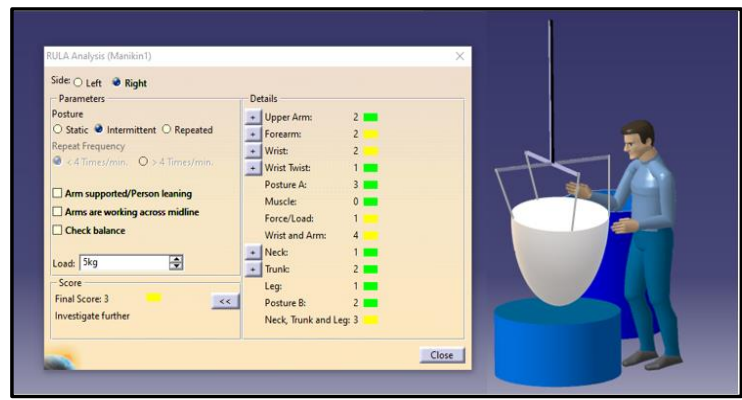

Gambar 2. Evaluasi Postur Kerja Penyaringan Bubur Kedelai

Pada aktivitas penyaringan bubur kedelai, penilaian menggunakan RULA Analysis tersebut dapat diketahui bahwa apabila postur kerja didominasi oleh warna hijau yang berarti memiliki risiko rendah, sedangkan warna kuning memiliki risiko sedang. Skor lengan atas sebesar 2 (warna hijau), skor lengan bawah sebesar 2 (warna kuning), skor pergelangan tangan sebesar 1 (warna kuning), skor pergelangan tangan yang melintir sebesar 1 (warna hijau), skor untuk beban (load) sebesar 
1 (warna kuning), skor untuk pergelangan tangan dan lengan sebesar 4 (warna kuning), skor leher sebesar 1 (warna hijau), skor badan sebesar 2 (warna hijau) dan skor kaki sebesar 1 (warna hijau). Beban yang diterima pekerja selama proses menggoyang-goyangkan penyaring bubur kedelai sebesar $5 \mathrm{~kg}$ dengan kategori pekerjaan yaitu berselang, karena pekerja pada stasiun kerja penyaringan bubur kedelai, juga melakukan pekerjaan mencetak tahu. Sehingga ditentukan kategori postur kerja tersebut adalah berselang (intermittent). Berdasarkan kondisi tersebut skor akhir yang ditunjukkan oleh software CATIA V5 yaitu 3 (warna kuning) yang berarti postur kerja tersebut perlu pemeriksaan lebih lanjut (investigate further) dan perlu dilakukan perbaikan[14].

Perbaikan pada kondisi postur kerja penyaringan bubur kedelai usulan dari peneliti adalah merancang alat penyaring bubur kedelai dan alat press bubur kedelai yang sesuai dengan antropometri pekerja dengan mekanisme kerja kedua alat adalah memutar tuas. Perancangan alat ini dilakukan dengan menggunakan 7 langkah perancangan produk.

Pada masyarakat modern, aktivitas perancangan dan pembuatan produk dilakukan oleh orang yang berbeda. Dengan kata lain, orang yang merancang produk dan orang yang membuat produk adalah tidak sama. Oleh karena itu, diperlukan suatu media yang berfungsi sebagai alat komunikasi antara perancang dan pembuat produk. Media komunukasi yang sangat efektif untuk digunakan adalah dengan menerapkan metode perancangan yang sistematis agar proses perancangan dan proses produksi berjalan dengan baik. Salah satu metode yang dapat digunakan yaitu metode Nigel Cross yang terdiri dari 7 tahap perancangan produk[15].

\subsection{Klarifikasi Tujuan}

Klarifikasi tujuan dilakukan untuk menentukan tujuan perancangan dan metode yang digunakan adalah objective tree. Didapatkan dari hasil kuesioner yang berupa keluhan dan keinginan dari konsumen. Alat penyaring dan alat press bubur kedelai yang ergonomis sesuai dengan keinginan konsumen adalah sebagai berikut :

1. Daftar perancangan produk secara keseluruhan antara lain: a. Alat penyaring dan alat press bubur kedelai mempunyai bahan yang kuat dan kokoh, serta mudah dibersihkan.

b. Alat penyaring dan alat press bubur kedelai mempunyai ukuran yang ergonomis dan elegan, serta sesuai dengan antropometri pekerja.

c. Alat penyaring dan alat press bubur kedelai mempunyai fungsi dan kualitas yang baik.

2. Urutan daftar tujuan dan sub tujuan produk, yaitu:

a. Atribut bahan yang berhubungan dengan bahan baku produk.

b. Atribut pengoperasian yang berhubungan dengan sistem.

c. Atribut desain berhubungan dengan rancangan fisik produk.

Dari data tujuan perancangan yang telah diklasifikasikan maka selanjutnya akan dibuat pohon tujuan dari atribut bahan yang dapat dilihat pada Gambar 3

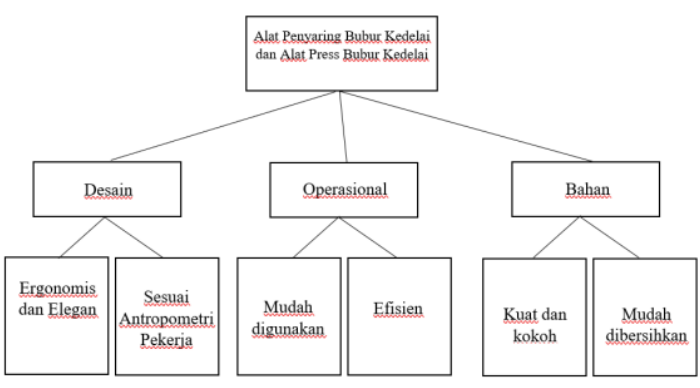

Gambar 3. Pohon Tujuan

\subsection{Penetapan Fungsi}

Karakteristik perancangan mengalami perubahan seiring berjalannya waktu. Pada masyarakat tradisional, aktivitas perancangan dilakukan oleh orang yang sama dengan pembuat produk. Pada kondisi tersebut, tidak diperlukan adanya model seperti gambar sebagai media komunikasi rancangan.

Dalam hal ini meliputi penetapan fungsi secara umum dan pengelompokkan sub-sub fungsi yang disajikan dalam black box yang ditunjukkan pada Gambar 4.

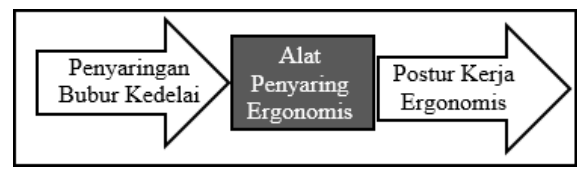

Gambar 4. Diagram Black Box 


\subsection{Penetapan Kebutuhan}

Setelah fungsi ditetapkan, maka langkah selanjutnya adalah menetapkan kebutuhan. Target spesifikasi dibuat setelah kebutuhan pelanggan diidentifikasikan yaitu berupa spesifikasi performance dan desain yang ergonomis.

\subsection{Penetapan Karakteristik Teknis}

Pada tahap ini kriteri-kriteria diterjemahkan kedalam kriteria teknik (karakteristik teknik) untuk memudahkan sebuah perancangan dan penyelesaian masalah. Penilaian karakteristik teknis ini terdiri dari beberapa hal yaitu, nyaman untuk digunakan, penyesuaian dengan ukuran antropometri, pemiliahan material, desain alat penyaring dan alat press bubur kedelai, dan aman.

\subsection{Penentuan Alternatif}

Penentuan alternatif merupakan sejumlah solusi rancangan berupa konsep-konsep yang ingin diterapkan sebagai alternatif pilihan dari alat penyaring bubur kedelai dan alat press bubur kedelai. Morfologi chart alat penyaring bubur kedelai ditunjukkan pada Gambar 5.

\begin{tabular}{|c|c|c|c|}
\hline \multirow{2}{*}{ Atribut Fungsi } & \multicolumn{3}{|c|}{ Alternatif konsep untuk mencapai fungsi } \\
\cline { 2 - 4 } & Konsep 1 & Konsep 2 & Konsep 3 \\
\hline Model alat penyaring & Single Person & Multi Person & \\
\hline Bentuk alat saring & Kubus & Tabung & \\
\hline Tuas alat penyaring & Tetap & Adjustable & \\
\hline Material alat saring & Aluminium & Plastik & Besi \\
\hline Tinggi alat saring & Sesuai & Sesuai & \\
Antropometri & Infrastruktur & \\
\hline Keterangan : & \multicolumn{3}{|c}{} \\
Alternatif 1: & \\
Alternatif 2: & \\
Alternatif 3: & & & \\
\end{tabular}

Gambar 5. Morfologi Alat Penyaring Bubur Kedelai

Morfologi chart alat press bubur kedelai ditunjukkan pada Gambar 6.

\begin{tabular}{|c|c|c|c|}
\hline \multirow{2}{*}{ Atribut Fungsi } & \multicolumn{3}{|c|}{ Alternatif konsep untuk mencapai fungsi } \\
\cline { 2 - 4 } & Konsep 1 & Konsep 2 & Konsep 3 \\
\hline Model alat press & Single Person & Multi Person & \\
\hline Bentuk alat press & Kerucut & Tabung & \\
\hline Tuas alat press & Tetap & Adjustable & \\
\hline Material alat press & Aluminium & Kayu & Besi \\
\hline Tinggi alat press & $\begin{array}{c}\text { Sesuai } \\
\text { Antropometri }\end{array}$ & Sesuai & \\
\hline Keterangan $:$ & & & \\
Alternatif $1: \longrightarrow$ & \\
Alternatif $2:$ & \\
Alternatif 3: &
\end{tabular}

Gambar 6. Morfologi Alat Press Bubur Kedelai

\subsection{Evaluasi Alternatif}

Pada tahap ini akan membandingkan nilai utilitas dari proposal alternatif rancangan berdasarkan performansi dan pembobotan yang berbeda. Dari keempat alternatif diatas yang merupakan kombinasi dari konsep sub-fungsi, dilakukan seleksi konsep untuk mengetahui alternatif yang sesuai dengan tujuan awal. Berdasarkan evaluasi alternatif ditetapkan pada alat penyaring bubur kedelai, alternatif terpilih yaitu alternatif 1 dengan spesifikasi (model alat penyaring bubur kedelai single person, bentuk alat saring yaitu tabung, tuas alat penyaring yaitu adjustable, material alat saring dari aluminium dan tinggi alat penyaring sesuai anthropometri.

Sedangkan berdasarkan evaluasi alternatif ditetapkan pada alat press bubur kedelai, alternatif terpilih yaitu alternatif 1 dengan spesifikasi (model alat press bubur kedelai single person, bentuk alat press yaitu tabung, tuas alat penyaring yaitu adjustable, material alat saring dari aluminium dan tinggi alat penyaring sesuai anthropometri.

\subsection{Perbaikan Rinci}

Perbaikan rinci merupakan tahap akhir dari langkah metode rasional perancangan dimana pada tahap ini alat penyaring dan alat press bubur kedelai akan didesain sesuai dengan hasil dari tahap-tahap sebelumnya. Langkah awal perancangan pada tahap ini yaitu menetukan ukuran antropometri pengguna dengan menggunakan konsep persentil. Konsep persentil diawali dengan mengumpulkan data antropometri pekerja yang ditunjukkan pada Tabel 2.

Tabel 2. Antropometri Pekerja

\begin{tabular}{|c|l|c|c|}
\hline \multirow{2}{*}{ No } & \multirow{2}{*}{ Bagian Tubuh } & \multicolumn{2}{|c|}{ Nama Pekerja } \\
\cline { 3 - 4 } & & Sandi & Alfin \\
\hline 1 & Lebar bahu (lb) & $42,4 \mathrm{~cm}$ & $48 \mathrm{~cm}$ \\
\hline 2 & $\begin{array}{l}\text { Diameter lingkar } \\
\text { genggam (dlg) }\end{array}$ & $6,5 \mathrm{~cm}$ & $4,6 \mathrm{~cm}$ \\
\hline 3 & $\begin{array}{l}\text { Tinggi bahu } \\
\text { berdiri (tbb) }\end{array}$ & $157 \mathrm{~cm}$ & $132 \mathrm{~cm}$ \\
\hline 4 & Lebar tangan (lt) & $9 \mathrm{~cm}$ & $8,8 \mathrm{~cm}$ \\
\hline 5 & $\begin{array}{l}\text { Tinggi siku } \\
\text { berdiri (tsb) }\end{array}$ & $101 \mathrm{~cm}$ & $99 \mathrm{~cm}$ \\
\hline
\end{tabular}

Setelah didapatkan data antropometri pekerja, dilakukan perhitungan rata-rata dan standar deviasi. Rumus untuk menghitung ratarata dan standar deviasai sebagai berikut[16]. 
$\overline{\mathrm{X}}=1 / \mathrm{n} \sum_{\mathrm{i}=1}^{\mathrm{n}} \mathrm{xi}$

dengan $: X i=$ nilai pengukuran dari suatu variat $\bar{X}=$ rata-rata hitung

$\mathrm{Sx}=\sqrt{\frac{\sum_{1-\mathrm{n}}^{\mathrm{n}}(\mathrm{Xi}-\overline{\mathrm{X}})^{2}}{\mathrm{n}-1}}$

dengan : $\quad X i=$ nilai pengukuran dari suatu variat

$\bar{X}=$ rata-rata hitung

$S x=$ standar deviasi

$n=$ jumlah data

Selanjutnya dapat dilakukan perhitungan persentil untuk mengetahui ukuran alat yang nantinya akan dirancang. Persentil yang digunakan pada penelitian ini adalah persentil 5, persentil 50 dan persentil 95 dengan rumus perhitungannya ditunjukkan pada Tabel 3 .

Tabel 3. Rumus Persentil

\begin{tabular}{|c|c|}
\hline Persentil & Perhitungan \\
\hline $5^{\text {st }}$ & $\overline{\mathrm{X}}-1,645 . \mathrm{SD}$ \\
\hline $50^{\text {st }}$ & $\overline{\mathrm{X}}$ \\
\hline $95^{\text {st }}$ & $\overline{\mathrm{X}}+1,645 . \mathrm{SD}$ \\
\hline
\end{tabular}

Hasil perhitungan yang telah dilakukan berdasarkan rumus persentil tersebut disajikan pada Tabel 4.

Tabel 4. Hasil Perhitungan Persentil

\begin{tabular}{|c|l|c|c|c|c|}
\hline No & $\begin{array}{c}\text { Data } \\
\text { yang } \\
\text { diukur }\end{array}$ & SD & P5 & P50 & P95 \\
\hline 1 & $\begin{array}{l}\text { Lebar } \\
\text { bahu }\end{array}$ & 3,959 & 38,688 & 45,2 & 51,712 \\
\hline 2 & $\begin{array}{l}\text { Diameter } \\
\text { lingkar } \\
\text { genggam }\end{array}$ & 1,343 & 3,340 & 5,55 & 7,759 \\
\hline 3 & $\begin{array}{l}\text { Tinggi } \\
\text { bahu } \\
\text { berdiri }\end{array}$ & 17,677 & 115,421 & 144,5 & 173,578 \\
\hline 4 & $\begin{array}{l}\text { Lebar } \\
\text { tangan }\end{array}$ & 0,141 & 8,668 & 8,9 & 9,131 \\
\hline 5 & $\begin{array}{l}\text { Tinggi } \\
\text { siku } \\
\text { berdiri }\end{array}$ & 1,414 & 97,673 & 100 & 102,326 \\
\hline
\end{tabular}

Hasil perhitungan persentil tersebut akan digunakan untuk menentukan ukuran panjang alat saring, tinggi alat saring, tebal engkol (tuas) dan panjang engkol. Berikut ini merupakan hasil perhitungan dari masing-masing ukuran dimensi alat penyaring bubur kedelai.

Panjang alat saring $\quad=\mathrm{lb}(\mathrm{P} 95)$

$$
=51,712 \mathrm{~cm}
$$

Ketinggian alat saring $=\operatorname{tbb}(\mathrm{P} 5) \pm$ allowance
- ketingian wadah penampung bubur kedelai

$=115,421+5-70$

$=50,421 \mathrm{~cm}$

Diameter engkol $\quad=\mathrm{dlg}(\mathrm{P} 5)$

$=3,340 \mathrm{~cm}$

Panjang engkol $\quad=1 \mathrm{t}(\mathrm{P} 95)$

$=9,131$

Berdasarkan hasil perhitungan ukuran dimensi dari alat penyaring bubur kedelai, dapat diketahui tampak atas alat penyaring bubur kedelai ditunjukkan pada Gambar 7.

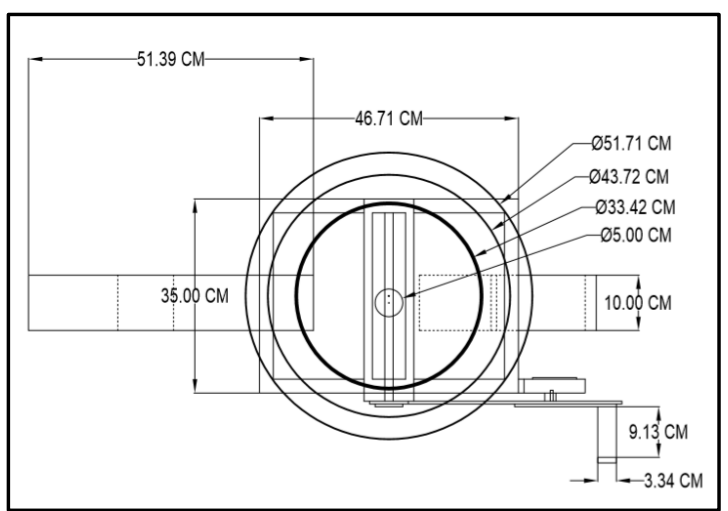

Gambar 7. Tampak Atas Alat Penyaring Bubur Kedelai

Tampak depan alat penyaring bubur kedelai ditunjukkan pada Gambar 8.

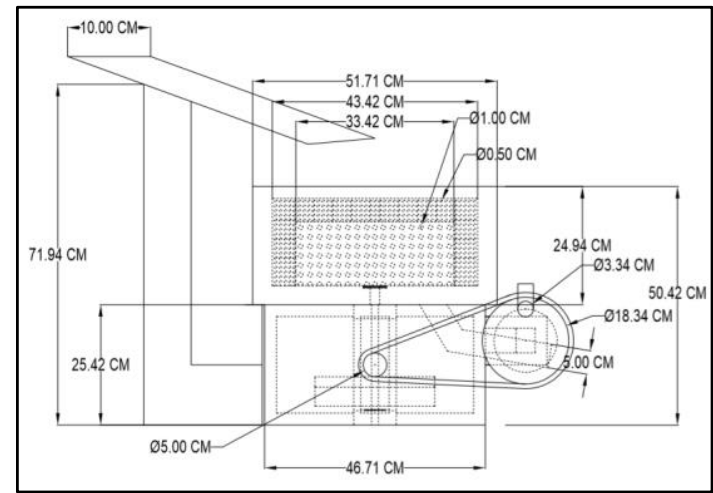

Gambar 8. Tampak Depan Alat Penyaring Bubur Kedelai

Tampak samping alat penyaring bubur kedelai ditunjukkan pada Gambar 9. 


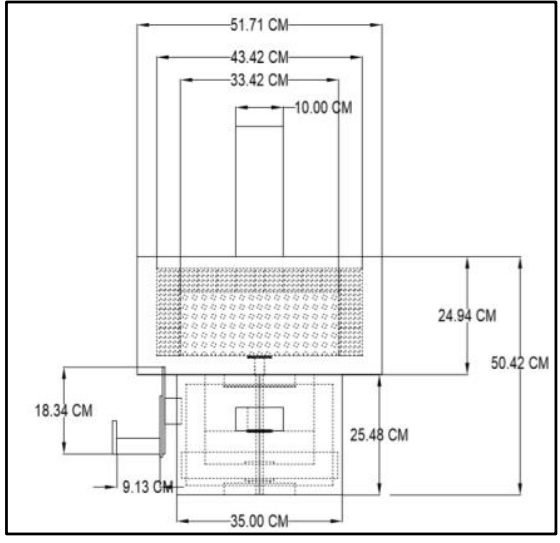

Gambar 9. Tampak Samping Alat Penyaring Bubur Kedelai

Tampak 3D alat penyaring bubur kedelai hasil desain menggunakan software CATIA V5 ditunjukkan pada Gambar 10.

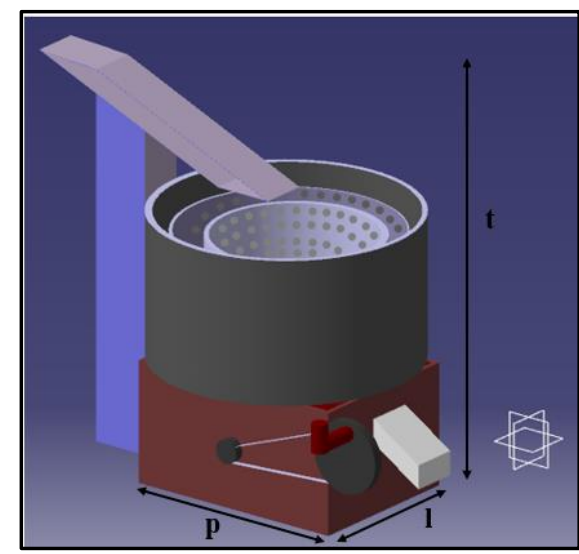

Gambar 10. Tampak 3D Alat Penyaring Bubur Kedelai

Pada rangakian proses penyaringan bubur kedelai, pekerja juga melakukan pengepressan bubur kedelai yang sudah berupa ampas tahu agar dapat dipastikan bahwa ampas tersebut tidak mengeluarkan cairan bubur kedelai lagi. Peneliti juga mengusulkan alat press bubur kedelai agar dapat mengurangi postur kerja tidak ergonomis dengan mengikuti ukuran dimensi alat press bubur kedelai yang sama seperti alat penyaring bubur kedelai. Ukuran dimensi alat press tersebut sebagai berikut.

$$
\begin{aligned}
\text { Panjang alat saring } & =\mathrm{lb}(\mathrm{P} 95) \\
& =51,712 \mathrm{~cm}
\end{aligned}
$$

Ketinggian alat saring $=\mathrm{tbb}(\mathrm{P} 5) \pm$ allowance

- ketingian wadah penampung bubur kedelai

$$
=115,421+5-70
$$

Diameter engkol

$$
=50,421 \mathrm{~cm}
$$

$$
=\mathrm{dlg}(\mathrm{P} 5)
$$$$
=3,340 \mathrm{~cm}
$$

$$
\begin{aligned}
\text { Panjang engkol } & =1 \mathrm{t}(\mathrm{P} 95) \\
& =9,131
\end{aligned}
$$

Berdasarkan hasil perhitungan ukuran dimensi dari alat press bubur kedelai, dapat diketahui tampak atas alat press bubur kedelai ditunjukkan pada Gambar 11.

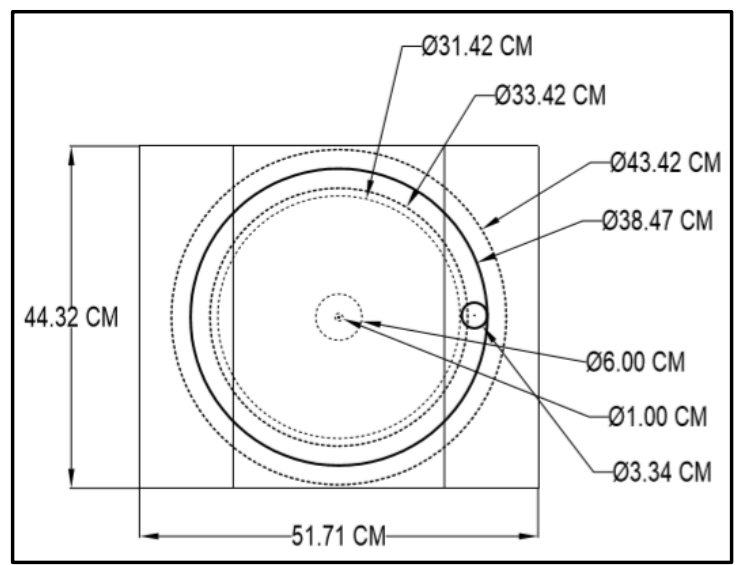

Gambar 11. Tampak Atas Alat Press Bubur Kedelai

Tampak depan alat press bubur kedelai ditunjukkan pada Gambar 12.

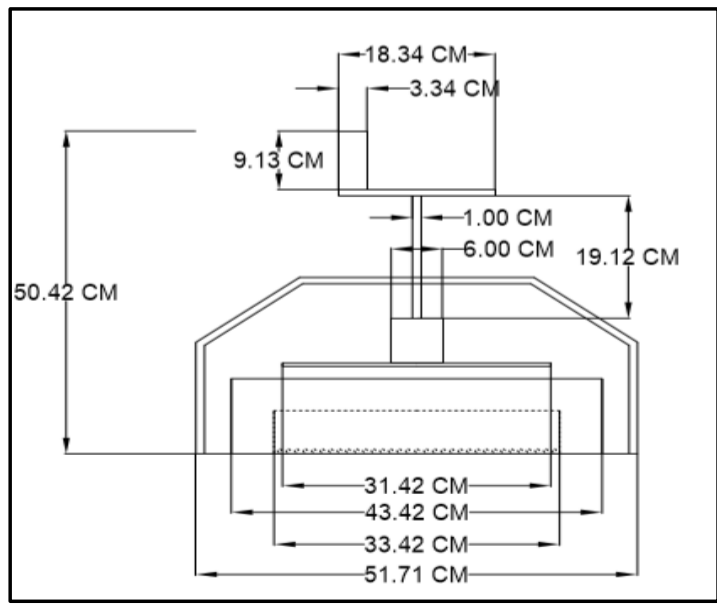

Gambar 12. Tampak Depan Alat Press Bubur Kedelai

Tampak samping alat press bubur kedelai ditunjukkan pada Gambar 13. 


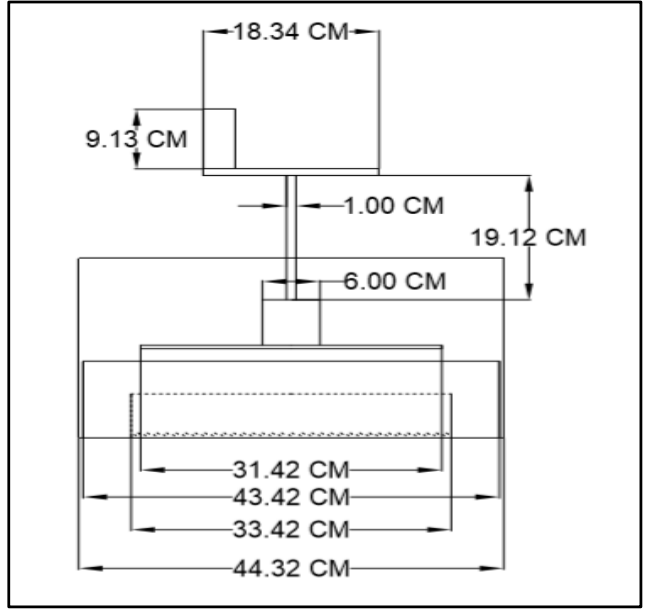

Gambar 13. Tampak Samping Alat Press Bubur Kedelai

Tampak 3D alat press bubur kedelai hasil desain menggunakan software CATIA V5 ditunjukkan pada Gambar 14.

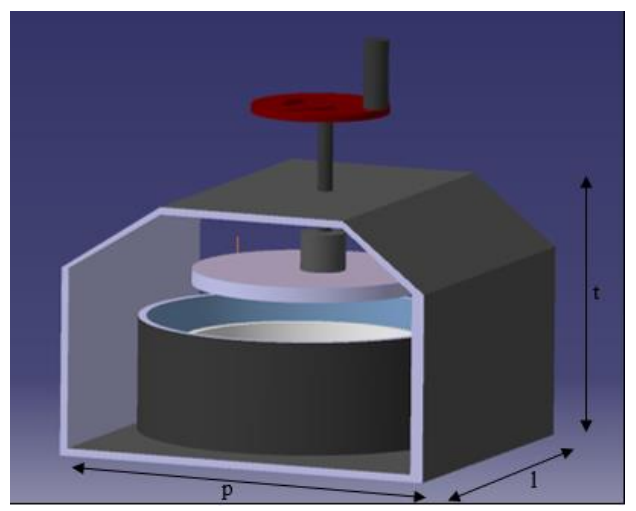

Gambar 14. Tampak 3D Alat Press Bubur Kedelai

Berdasarkan hasil rancangan alat penyaring bubur kedelai dan alat press bubur kedelai dari peneliti, maka dapat dilakukan perbandingna kondisi awal dan kondisi sebelum penggunaan kedua alat tersebut. Hasil analisis dari penggunaan alat penyaring bubur kedelai awal sebelum penggunaan alat rancangan dari peneliti dapat dilihat pada Gambar 15.

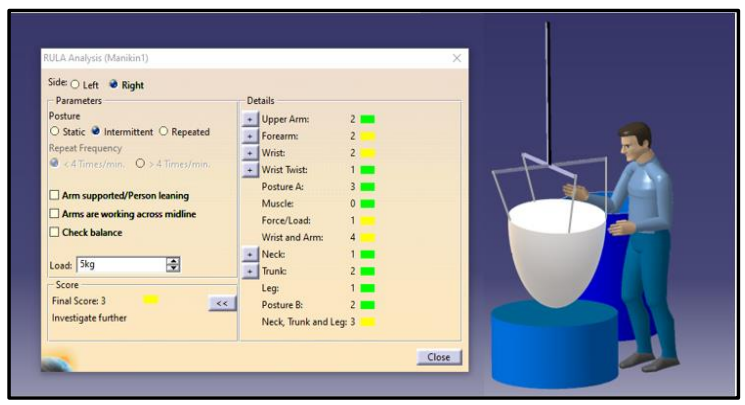

Gambar 15. Kondisi Awal Alat Penyaring Bubur Kedelai
Hasil analisis dari penggunaan alat penyaring bubur kedelai setelah penggunaan alat rancangan dari peneliti dapat dilihat pada Gambar 16.

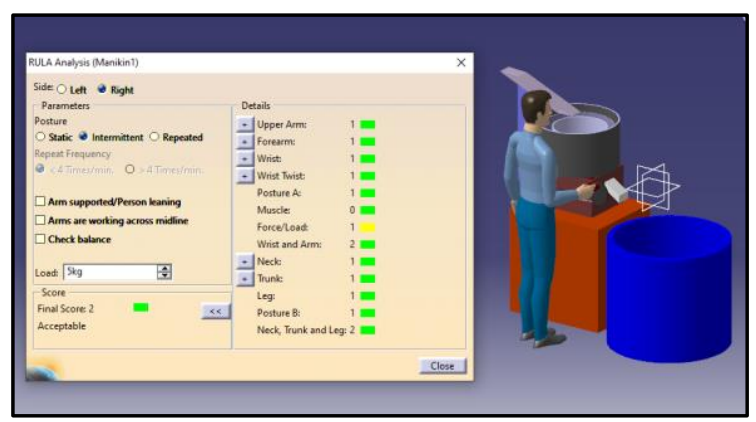

Gambar 16. Kondisi Setelah Penggunaan Alat Penyaring Bubur Kedelai

Berdasarkan hasil analisis yang dilakukan pada kondisi awal dan kondisi usulan, dapat diketahui bahwa perbaikan pada fasilitas kerja berupa perancangan alat penyaring bubur kedelai oleh peneliti, memberikan skor yang lebih baik dengan skor sebesar 2 yang berarti postur kerja tersebut aman dan diperbolehkan (acceptable) dibandingkan dengan kondisi awal yang menghasilkan skor sebesar 3 yang berarti perlu adanya pemeriksaan lebih lanjut pada postur tersebut (investigate further).

Hasil analisis dari penggunaan alat press bubur kedelai awal sebelum penggunaan alat rancangan dari peneliti dapat dilihat pada Gambar 17.

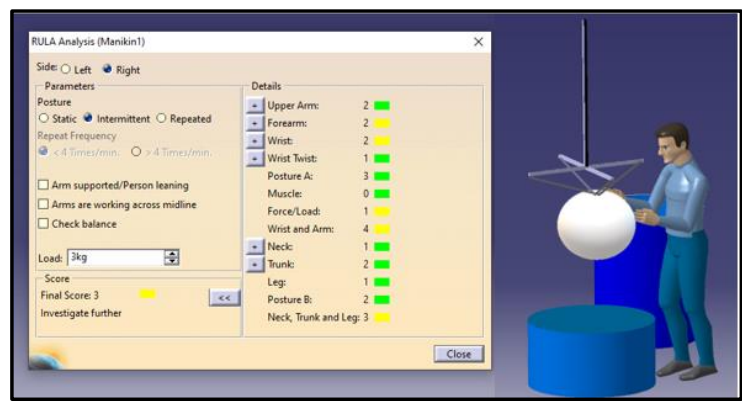

Gambar 17. Kondisi Awal Alat Press Bubur Kedelai

Hasil analisis dari penggunaan alat press bubur kedelai setelah penggunaan alat rancangan dari peneliti dapat dilihat pada Gambar 18. 


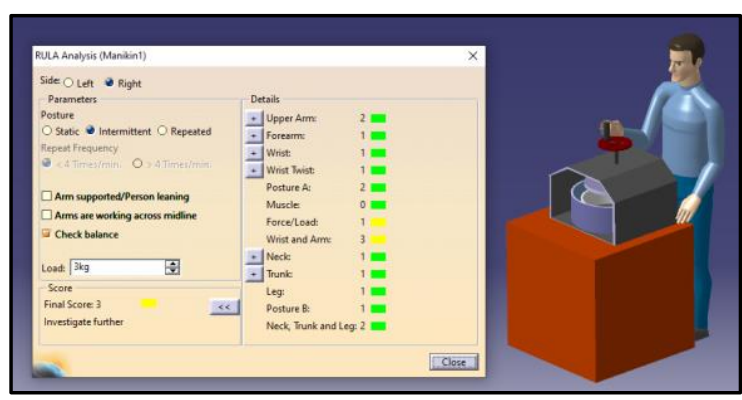

Gambar 18. Kondisi Setelah Penggunaan Alat Press Bubur Kedelai

Berdasarkan hasil analisis yang dilakukan pada kondisi awal dan kondisi usulan, dapat diketahui bahwa perbaikan pada fasilitas kerja berupa perancangan alat pengepress bubur kedelai oleh peneliti, memberikan skor yang sama dengan skor kondisi awal proses pengepressan kedelai yaitu sebesar 3 yang berarti perlu adanya pemeriksaan lebih lanjut pada postur tersebut (investigate further). Namun pada kondisi usulan jumlah poin yang berwarna kuning (risiko sedang) jumlahnya yaitu 2 poin sedangkan kondisi awal berjumlah 5 poin, kondisi usulan lebih baik daripada kondisi awal pada proses pengepressan bubur kedelai. Berdasarkan hal tersebut sebaiknya pekerja dapat menggunakan alat press bubur kedelai hasil rancangan peneliti agar nantinya dapat mengurangi keluhan musculoskeletal pada segmen-segmen tubuh tertentu walaupun efek yang ditimbulkan tidak terlalu signifikan.

Dengan penggunaan validasi trial ini dapat diketahui perbandingan dari kondisi awal dan kondisi akhir, serta dapat diketahui seberapa signifikan perubahan yang terjadi akibat dari perubahan yang telah dilakukan.

\section{Kesimpulan dan Saran}

Pada Pabrik Tahu Pak Kasimin, terdapat postur kerja yang tidak ergonomis pada stasiun kerja penyaringan bubur kedelai dengan postur kerja membungkuk, kondisi leher yang miring dengan sudut $126,58^{\circ}$, siku kiri dan kanan dengan flexi $42^{\circ}$, dan bahu kanan dan kiri terangkat $47^{\circ}$. Berdasarkan hal tersebut postur kerja dari pekerja pabrik tahu tergolong sebagai postur kerja tidak ergonomis.

Usulan perbaikan stasiun kerja yang dilakukan peneliti yaitu pembuatan alat penyaring bubur kedelai dan alat press bubur kedelai yang dengan model single person, bentuk alat saring dan alat press yaitu berbentuk tabung, tuas alat penyaring dan alat press adjustable, material alat saring dan alat press yaitu aluminium, tinggi alat penyaring dan alat press di sesuaikan antropometri pengguna. Mekanisme kerja alat tersebut berbeda pada saat proses penyaringan bubur kedelai di Pabrik Tahu Pak Kasimin. Alat hasil rancangan yang didesain menggunakan software CATIA V5 dengan memperhatikan antropometri pekerja ini menggunakan sistem engkol untuk mengurangi postur kerja yang tidak ergonomis pada pekerja

Saran untuk usaha pabrik tahu dari peneliti yaitu pemilik pabrik dapat mempertimbangkan penggunaan alat penyaring dan alat press bubur kedelai ini untuk nantinya dapat digunakan pada pabrik tahu tersebut, penggunaan alat rancangan dari peneliti ini nantinya dapat mengurangi keluhan musculoskeletal pada pekerja pabrik. Saran untuk penelitian selanjutnya, penelitian yang telah dilakukan oleh peneliti pada saat ini dapat dikombinasikan dengan perhitungan konsumsi energi oleh pekerja sehingga nantinya dapat diketahui perbandingan konsumsi energi dalam penggunaan alat penyaring bubur kedelai pada saat ini yang sedang digunakan oleh Pabrik Tahu Pak Kasimin dan konsumsi energi setelah penggunaan alat penyaring bubur kedelai hasil rancangan peneliti.

\section{Daftar Pustaka}

[1] A. Anjanny, A. Ferusgel, dan D. M. S. Siregar, "Keluhan Musculoskeletal Disorders (MSDs) Pada Pekerjaan Penggunaan Komputer di Badan Pusat Statistik Provinsi Sumatera Utara," J. Kesehat. Glob., vol. 2, no. 1, hal. 4551, 2019.

[2] L. D. Fathimmahayati, M. R. Wardana, dan N. A. Gumilar, "Analisis Risiko K3 dengan Metode HIRARC pada Industri Tahu dan Tempe Kelurahan Selili, Samarinda," J. Rekayasa dan Inov. Tek. Ind., vol. 7, no. 1, 2019.

[3] W. S. Kuswana, Ergonomi dan K3 Kesehatan dan Keselamatan Kerja. Bandung: PT. Remaja Rosdakarya, 2014.

[4] Yanto dan B. Ngaliman, Ergonomi Dasar-Dasar Studi Waktu \& Gerakan untuk Analisis dan Perbaikan Sistem Kerja. Yogyakarta: CV. Andi Offset, 2017.

[5] Tarwaka, S. HA Bakri, dan L. Sudiajeng, Ergonomi Untuk Keselamatan, Kesehatan Kerja dan 
Produktivitas. Surakarta: UNIBA Press, 2004.

[6] A. Mutiah, Y. Setyaningsih, dan S. Jayanti, "Analisis Tingkat Risiko Musculoskeletal Disorders (MSDs) dengan The BRIEFTM Survey dan Karakteristik Individu Terhadap Keluhan MSDs Pembuat Wajan Di Desa Cepogo Boyolali," J. Kesehat. Masy., vol. 2, no. April, 2013.

[7] P. Wahyudi dan W. Hariyono, "Kesesuaian Manual Assessement Chart Tool dan NIOSH Lifting Equation Dalam Identifikasi Keluhan Muskuloskeletal Pekerja Industri," BKM J. Community Med. Public Heal., vol. 33, hal. 377-382, 2017.

[8] D. A. Anggraini dan N. C. Bati, “Analisa Postur Kerja Dengan Nordic Body Map \& Reba Pada Teknisi Painting Di PT. Jakarta Teknologi Utama Motor Pekanbaru," J. Phot., vol. 7, no. 1, 2016.

[9] A. N. Bintang dan S. K. Dewi, "Analisa Postur Kerja Menggunakan Metode OWAS dan RULA," J. Tek. Ind., vol. 18, no. 01, hal. 43-54, 2017.

[10] S. Wignjosoebroto, Ergonomi Studi Gerak dan Waktu. Surabaya: Prima Printing, 1995.

[11] H. Iridiastadi dan Yassierli, Ergonomi Suatu Pengantar. Bandung: PT. Remaja Rosdakarya, 2014.

[12] Nofirza dan D. Syahputra, "Perancangan Alat Pemotong Nenas Yang Ergonomis Untuk Meningkatkan Produktivitas," J. Ilm. Tek. Ind., vol. 11, no. 1, hal. 41-50, 2012.

[13] F. Sulaiman, "Desain Produk: Rancangan Tempat Lilin Multifungsi Dengan Pendekatan 7 Langkah Nigel Cross," J. Teknovasi, vol. 4, no. 1, hal. 32-41, 2017.

[14] N. M. Dewantari, "Analisis postur Kerja Dengan Metode Rapid Upper Limb Assesment ( RULA ) Pada Operator," J. Optimasi Tek. Ind., vol. 1, no. 2, hal. 6-9, 2019.

[15] G. O. Dharma, D. R. Luxitasari, dan M. S. A. Khannan, "Perancangan Ulang Headset dan Penutup Mata Untuk Tidur Menggunakan Metode Nigel Cross," J. Optimasi Sist. Ind., vol. 11, no. 1, hal. 65-77, 2018.

[16] E. Yusniyanti dan Kurniati, "Analisa
Puncak Banjir Dengan Metode MAF (Studi Kasus Sungai Krueng Keureuto)," J. Einstein, vol. 5, no. 1, 2017. 
Wardana et all/MATRIK. Vol.XXI, No.1, September 2020, Halaman 29-40

(Halaman ini sengaja dikosongkan) 